\title{
Pengaruh Profitabilitas, Leverage, Ukuran Perusahaan, Sales Growth, dan Kualitas Audit Terhadap Tax Avoidance
}

Tri Wahyuni ${ }^{1}$, Djoko Wahyudi ${ }^{2}$

${ }^{1}$ Fakultas Ekonomika dan Bisnis Akuntansi, Universitas Stikubank Semarang

e-mail: triw2313@gmail.com

${ }^{2}$ Fakultas Ekonomika dan Bisnis Akuntansi, Universitas Stikubank Semarang

e-mail: djokowahjudi7@gmail.com

\section{ARTICLE INFO}

Article history:

Received 30 September 2021

Received in revised form 2 November 2021

Accepted 10 November 2021

Available online 1 Desember 2021

\author{
ABSTRACT
}

Taxes becomes very important because taxes provide a large contribution to state revenues. This study aims to analyze the influence of profitability, leverage, firm size, sales growth dan audit quality to tax avoidance. The sample of this study were Indonesia Stock Exchange registered manufacture companies in 2017 until 2019 thus 213 data were used in this study. descriptive statistical test and multiple regression tests with the SPSS 26 were used to analyze the data. This study showed that the independent variabel profitability has a significant positive effect on tax avoidance, leverage has a significant negative on tax avoidance. On the other hand, firm size, sales growth and audit quality does not affect the tax avoidance variable

Keywords: Tax Avoidance, Profitabilitas, Leverage, Ukuran Perusahaan, Sales Growth, Kualitas Audit

\section{Pendahuluan}

Pajak merupakan kontribusi besar bagi penerimaan negara Indonesia. Pajak mendukung adanya kemandirian finansial negara. Pajak memiliki sifat memaksa sehingga seorang wajib pajak wajib menyetorkan pajak kepada negara.pendapatan pajak akan dikontribusikan oleh negara untuk pembangunan nasional agar tercapai kesejahteraan untuk rakyat Indonesia. Pendapatan pajak juga dipergunakan untuk mengatur besar kecilnya anggaran yang akan dikeluarkan oleh negara dalam pembiayaan pembangunan maupun anggaran rutin pemerintah (Aprianto \& Dwimulyani, 2019).

Perbedaan pandangan dan tujuan antara pihak fiscus dengan pihak wajib pajak badan usaha seringkali menimbulkan gagasan baru mengenai perpajakan yang ada di Indonesia. Fiscus harus memperoleh pelaporan dan pembayaran pajak secara optimal dari wajib pajak sedangkan perusahaan harus memperoleh laba dengan maksimal untuk melanjutkn kelangsungan hidup perusahaan (Mahdiana \& Amin, 2020).

Dengan adanya praktik tax avoidance di Indonesia, menyebabkan negara Indonesia mengalami banyak kerugian. Lembaga Tax Justice Network melaporkan bahwa perusahaan tembakau milik British American Tobacco (BAT) melakukan tax avoidance di Indonesia 
sehingga negara mengalami kerugian sebesar US\$ 14 juta pertahun. Dalam laporan tax Justice Network melaporakan bahwa BAT mengalihkan sebagian pendapatannya keluar dari Indonesia dengan dua cara yaitu pinjaman intra-perusahaan antara tahun 2013-2015. Yang kedua melalui pembayaran kembali ke inggris untuk royalty, ongkos, dan layanan.

Penerimaan negara berasal dari pajak yang dianggap sebagai tulang punggung negara. Tax avoidance merupakan langkah-langkah yang dilakukan oleh wajib pajak badan maupun wajib pajak orang pribadi untuk menghindari pajak namun dengan cara-cara yang legal (Mahdiana \& Amin, 2020).

Profitabilitas merupakan salah satu indikator yang digunakan untuk menilai kinerja perusahaan didalam mengelola laba kekayaan yang dimiliki perusahaan dengan tujuan untuk menghasilkan laba secara maksimal dalam periode tertentu (Irianto et al., 2017). Perusahaan memiliki tujuan utama yaitu dalam melakukan kegiatan usahanya memperoleh laba yang maksimal. Didalam penelitian yang dilakukan oleh (Prapitasari \& Safrida, 2019), (Mahdiana \& Amin, 2020), (Anggraeni \& Oktaviani, 2021) yang menyatakan bahwa profitabilitas berpengaruh signfikan terhadap tax avoidance. Namun berbeda dengan hasil penelitian (Wahyuni et al., 2017) yang menyatakan bahwa profitabilitas tidak berpengaruh signifikan terhadap tax avoidance.

Leverage merupakan rasio yang digunakan untuk menganalisis kemampuan perusahaan untuk melunasi hutang jangka pendek maupun jangka panjang (Arinda \& Dwimulyani, 2018). Rasio leverage digunakan untuk mengukur seberapa besar perusahaan dibiayai dengan hutang. Didalam penelitian (Mahdiana \& Amin, 2020),(Wahyuni et al., 2017) menyatakan bahwa leverage berpengearuh signifikan terhadap tax avoidance. Sedangakan didalam penelitian (Prapitasari \& Safrida, 2019), (Hidayat, 2018) menyatakan bahwa leverage tidak berpengaruh signifikan terhadap tax avoidance.

Ukuran perusahaan merupakan salah satu faktor yang mempengaruhi tax avoidance. Apabila ukuran perusahaan semakin besar maka akan memunculkan adanya pengelolaan pajak dengan baik. Hal tersebut akan menjadi sorotan pemerintah dikarenakan semakin besarnya ukuran perusahaan maka transaksi dalam perusahaan tersebut menjadi kompleks. Didalam penelitian (Irianto et al., 2017) dan (Diantari et al., 2021) menyatakan bahwa ukuran perusahaan berpengaruh signifikan terhadap tax avoidance. Sedangkan dalam penelitian (Primasari, 2019) dan (Mahdiana \& Amin, 2020) menyatakan bahwa ukuran perusahaan tidak berpengaruh terhadap tax avoidance.

Sales Growth menggambarkan keberhasilan perusahaan didalam melakukan investasi dan menjadi tolak ukur dengan adanya peningkatan penjualan. Apabila pertumbuhan penjualan suatu perusahaan mengalami penurunan maka perusahaan akan mengalami kendala dalam meningkatkan kapasitas operasinya. Didalam penelitian yang dilakukan (Wahyuni et al., 2017) menyatakan bahwa sales growth berpengaruh signifikan terhadp tax avoidance. Namun berbeda dengan penelitian oleh (Aprianto \& Dwimulyani, 2019) dan (Primasari, 2019) yang menyatakan bahwa sales growth tidak berpengaruh signifikan terhadap tax avoidance.

Kualitas Audit merupakan hal yang berhubungan dengan ukuran dari KAP, dimana KAP yang memasuki golongan big four biasanya memiliki kualitas audit yang lebih baik dibandingkan dengan non big four. Didalam penelitian yang dilakukan oleh (Sulistiono, 2018) menyatakan bahwa kualitas audit berpengaruh terhadap tax avoidance. sedangkan menurut (Arinda \& Dwimulyani, 2018) dan (Primasari, 2019) menyatakan bahwa kualitas audit tidak berpengaruh terhadap tax avoidance.

Teori Agensi menurut (Michael C Jensen \& Meckling, 1976) merupakan suatu kontrak yang melibatkan pemberi kewenangan (principal) dengan penerima kewenangan (agent). Principal mendelegasikan wewenang kepada agent dalam mengelola perusahaan serta dalam segala jenis bentuk pengambilan keputusan untuk perusahaan. teori ini menjelaskan hubungan yang terdapat didalam perusahaan yaitu antara pemilik perusahaan (principal) dengan manajer perusahaan (agent). Teori agensi dalam tax avoidance dapat dilihat dari sisi manajer yang

JURNAL ILMIAH KOMPUTERISASI AKUNTANSI Vol. 14, No. 2, Desember 2021 : 394 - 403 
melakukan penghindaran pajak demi mencapai tujuan perusahaan didalam memperoleh laba yang maksimal.

Tax avoidance merupakan salah satu upaya legal yang dilakukan perusahaan dalam menghindari pajak. Teknik yang dilakukan dalam penghindaran pajak yaitu dengan memanfaatkan kelemahan-kelemahan yang terdapat pada undang-undang dan peraturan perpajakan untuk mengurangi beban pajak yang dibayarkan. Pajak memiliki difat yang memaksa sehingga waajib pajak tidak dapat menolak untuk tidak membayar pajak sehingga manajer melakukan penghindaran pajak agar memperoleh laba yang maksimal untuk memenuhi kepentingan manajerial maupun investor (Anggraeni \& Oktaviani, 2021)

Profitabilitas dianggap sebagai pengukuran kinerja internal perusahaan untuk mengelola kekayaan perusahaan (Arinda \& Dwimulyani, 2018). Profitabilitas dapat mengukur kinerja suatu perusahaan dalam menghasilkan laba. Rasio profitabilitas dalam pengukuran menggunakan return on asset (ROA) yang menggambarkan perusahaan memperoleh laba dengan menggunakan total asset yang dimiliki perusahaan. besar kecilnya laba yang dihasilkan oleh perusahaan tergantung oleh kinerja manajemen dalam mengelola keuangan. Berdasarkan teori tersebut semakin tinggi besar laba yang diperoleh perusahaan maka kinerja manajemen dijalankan dengan baik. Maka semakin besar peluang manajemen dalam melakukan tax avoidance. Didalam penelitian (Arinda \& Dwimulyani, 2018) dan (Prapitasari \& Safrida, 2019) (Anggraeni \& Oktaviani, 2021) menyatakan bahwa profitabilitas berpengaruh positif terhadap tax avoidance.

Leverage digunakan oleh perusahaan dalam menilai seberapa besar asset sebuah perusahaan yang didapat dengan menggunakan hutang (Kasmir, 2014). Leverage berguna untuk menganalisis kredit yang aman agar dapat diambil oleh perusahaan dalam pendanaan perusahaan tersebut. Leverage menggunakan rasio perhitungan debt to equity ratio (DER). Dalam teori agensi, principal memberikan wewenang kepada agen untuk mengambil keputusan yang baik demi perusahaan. hal inilah yang memacu manajemen dalam melakukan tax avoidance. Didalam penelitian (Arinda \& Dwimulyani, 2018) dan (Aprianto \& Dwimulyani, 2019) menyatakan bahwa leverage berpengaruh negatif terhadap tax avoidance.

Ukuran perusahaan menunjukkan kestabilan serta kemampuan perusahaan didalam melakukan ativitas ekonominya. Ukuran perusahaan dapat mengklasifikasikan besar kecilnya suatu perusahaan yang dilihat dari total asset yang dimiliki. Ukuran perusahaan dapat mempengaruhi kinerja manajemen serta sumber daya yang dimiliki perusahaan. dengan adanya sumber daya yang besar akan menghasilkan laba usaha yang besar. Sehingga dengan adanya laba yang besar akan mendorong pihak manajemen untuk melakukan tax avoidance agar dapat mencapai tujuan perusahaan. Didalam penelitian (Diantari et al., 2021) (Irianto et al., 2017) menyatakan bahwa ukuran perusahaan berpengaruh positif terhadap tax avoidance.

Sales growth merupakan hal yang sangat penting didalam penjualan produk maupun jasa perusahaan. dengan adanya tingkat penjualan yang tinggi akan menghasilkan pendapatan suatu perusahaan. sales growth mencerminkan keberhasilan alam investasi masa lalu yang dilakukan perusahaan dan digunakan sebagai proksi pertumbuhan masa yang akan datang dengan membandingkan indikator permintaan dan daya saing perusahaan dalam suatu industry. Dalam teori agensi, agent berkewajiban memenuhi tugasnya yaitu mencapai terget laba yang telah sesuai dengan kontrak antara agent dengan principal. Apabila sales growth meningkat dalam tahun ke tahun maka akan berdampak terhadap pembayaran pajak. Sehingga hal ini dapat memacu manajemen untuk melakukan tax avoidance. Didalam penelitian (Wahyuni et al., 2017) menyatakan bahwa sales growth berpengaruh positif terhadap tax avoidance.

Kualitas audit yang baik diberikan oleh auditor dengan memiliki kualitas dan kemampuan dalam audit yang baik. Kualitas audit dapat diukur berdasarkan besar kecilnya Kantor Akuntan Publik. Apabila perusahaan di audit oleh KAP big four dipercaya memiliki tingkat penghindaran

Pengaruh Profitabilitas, Leverage, Ukuran Perusahaan, Sales Growth, dan Kualitas Audit Terhadap Tax Avoidance (Tri Wahyuni) 
pajak yang kecil. Didalam penelitian (Feranika et al., 2016) menyatakan bahwa kualitas audit berpengaruh negatif terhadap tax avoidance.

Penelitian ini didasarkan pada profitabilitas, leverage, ukuran perusahaan, sales growth, kualitas audit terhadap tax avoidance. Berdasarkan teori yang telah di paparkan dapat disusun model penelitian sebagai berikut:

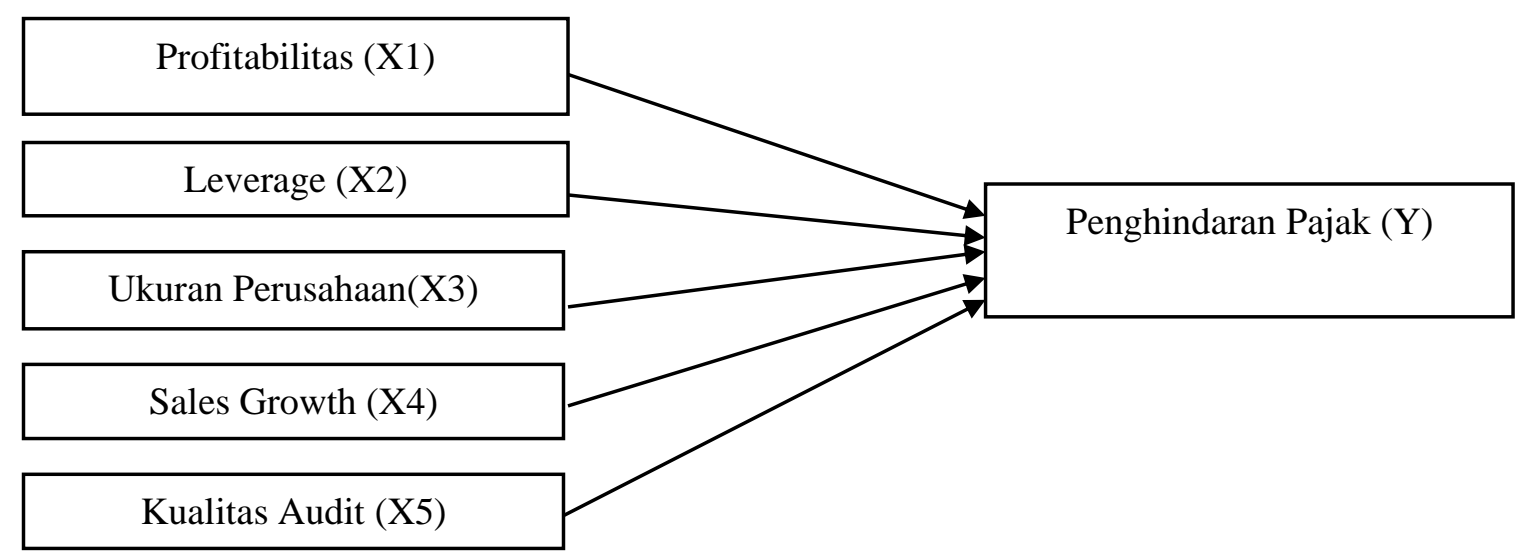

Gambar 1 Kerangka Penelitian

Hipotesis merupakan jawaban sementara terhadap permasalahan dalam suatu penelitian.

Hipotesis yang diuji dalam penelitian ini adalah:

H1: Profitabilitas berpengaruh positif terhadap tax avoidance

H2: Leverage berpengaruh negatif terhadap tax avoidance

H3: Ukuran Perusahaan berpengaruh positif terhadap tax avoidance

H4: Sales Growth berpengaruh positif terhadap tax avoidance

H5: Kualitas Audit berpengaruh negatif terhadap tax avoidance

\section{Metode Penelitian}

Pada penelitian ini menggunakan variabel dependen dan variabel independen. Variabel dependen adalah variabel yang dipengaruhi oleh variabel independen. Variabel dependen dalam penelitian ini adalah tax avoidance dan untuk variabel independen dalam penelitian ini adalah profitabilitas, leverage, ukuran perusahaan, sales growth dan kualitas audit.Berikut pemaaparan proksi dari masing - masing variabel:

Tax avoidance merupakan salah satu tindakan legal dalam mengurangi beban pajak yang ditanggung perusahaan. Tax avoidance dapat diukur menggunakan Effective Tax Rate (ETR)

$$
\text { ETR }=\frac{\text { beban pajak }}{\text { labasebelum pajak }}
$$

Profitabilitas berkaitan terkait dengan laba bersih dan asset yang dimiliki perusahaan. Profitabilitas dapat diukur dengan Return of Asset (ROA)

$$
\text { ROA }=\frac{\text { Laba Setelah Pajak }}{\text { Total Aset }}
$$

Leverage merupakan salah satu rasio yang dapat mengukur kemampuan hutang untuk membiayai ekuitas perusahaan. Leverage dapat diukur dengan Debt to Equity Ratio

$$
\text { DER }=\frac{\text { Total Liabilities }}{\text { Total Equity }}
$$

Ukuran perusahaan dikelompokan berdasarkan besar kecilnya ukuran suatu perusahaan. Ukuran perusahaan dapat diukur dengan logaritma natural total asset

$$
\text { Ukuran Perusahaan }=\text { Ln (Total Aset) }
$$

Sales growth mencerminkan kemampuan perusahaan dalam meningkatkan penjualan dari tahun ke tahun. Sales growth dapat dirumuskan sebagai berikut:

$$
\text { Sales growth }=\frac{\text { salesi }- \text { sales } 0}{\text { sales } \mathrm{n}}
$$


Kualitas audit memiliki keterikatan dengan ukuran KAP. KAP big four memiliki kualitas yang lebih baik dibandingkan KAP non big four. Kualitas audit diukur dengan nominal.

$0=\mathrm{KAP}$ non big four

$1=\mathrm{KAP}$ big four

Objek Penelitian, Unit Sampel, Populasi, dan Penentuan Sampel

Penelitian ini mengambil populasi perusahaan manufaktur yang terdaftar di Bursa Efek Indonesia selama periode 2017 - 2019. Teknik Sampling yang digunakan yaitu purposive sampling method dengan mempertimbangkan kriteria tertentu dan sesuai dengan tujuan penelitian. Kriteria sampel dalam penelitian ini sebagai berikut (1) perusahaan manufaktur yang terdaftar di Bursa Efek Indonesia Periode 2017 - 2019. (2) perusahaan manufaktur yang tidak menerbitkan laporan keuangannya selama periode 2017 - 2019. (3) perusahaan manufaktur yang mengalami kerugian pada tahun 2017 - 2019. (4) perusahaan manufaktur yang memiliki etr $<1$. (5) perusahaan manufaktur yang tidak mengalami sales growth.

\section{Hasil dan Pembahasan}

Populasi dalam penelitian ini yaitu perusahaan manufaktur yang terdaftar di Bursa Efek Indonesia selama periode 2017 - 2019. Pemilihan sampel menggunakan Teknik purposive sampling dengan kriteria khusus sebagai berikut:

Tabel 1. Kriteria Sampel

\begin{tabular}{|c|l|c|c|c|c|}
\hline No & \multicolumn{1}{|c|}{ Kriteria } & $\mathbf{2 0 1 7}$ & $\mathbf{2 0 1 8}$ & $\mathbf{2 0 1 9}$ & Jumlah \\
\hline 1. & Perusahaan yang terdaftar di BEI & 156 & 165 & 180 & 501 \\
\hline 2. & $\begin{array}{l}\text { Perusahaan manufaktur yang tidak } \\
\text { menerbitkan laporan keuangan selama } \\
\text { periode 2017 - 2019. }\end{array}$ & $(6)$ & $(17)$ & $(28)$ & $(51)$ \\
\hline 3. & $\begin{array}{l}\text { Perusahaan manufaktur yang mengalami } \\
\text { kerugian pada 2017, 2018 dan 2019 }\end{array}$ & $(48)$ & $(36)$ & $(45)$ & $(129)$ \\
\hline 4. & $\begin{array}{l}\text { Perusahaan manufaktur yang tidak } \\
\text { memiliki etr < 1 }\end{array}$ & $(3)$ & $(0)$ & $(1)$ & $(4)$ \\
\hline 5. & $\begin{array}{l}\text { Perusahaan manufaktur yang tidak } \\
\text { mengalami sales growth }\end{array}$ & $(23)$ & $(32)$ & $(49)$ & $(104)$ \\
\hline & \multicolumn{1}{|c|}{ Total Sampel } & $\mathbf{7 6}$ & $\mathbf{8 0}$ & $\mathbf{5 7}$ & $\mathbf{2 1 3}$ \\
\hline
\end{tabular}

\section{Statistik Deskriptif}

Statistik deskriptif digunakan untuk memberikan gambaran terkait dengan variable dependen dan variable independen yang digunakan dalam penelitian ini. Uji yang deskriptif yang digunakan antara lain mean (nilai rata - rata), nilai minimum, nilai maximum dan standar deviasi. Penelitian ini statistic deskriptif yang sudah dilakukan outlier agar dapat digunakan dalam penelitian ini dengan menggunakan 173 sampel.

Tabel 2. Statistik Deskriptif Setelah Outlier

\begin{tabular}{|l|c|r|r|r|r|}
\hline & $\mathrm{N}$ & Minimum & Maximum & \multicolumn{1}{c|}{ Mean } & \multicolumn{1}{c|}{ Std. Deviation } \\
\hline ETR & 173 &, 175 &, 342 &, 25617 &, 032693 \\
\hline ROA & 173 &, 001 &, 527 &, 09410 &, 083145 \\
\hline DER & 173 &, 091 & 3,513 &, 76880 &, 627519 \\
\hline UKURAN PERUSAHAAN & 173 & 21,017 & 33,474 & 28,80452 & 1,782660 \\
\hline SALES GROWTH & 173 &, 001 &, 911 &, 13641 &, 124974 \\
\hline UKURAN KAP & 173 &, 0 & 1,0 &, 457 &, 4496 \\
\hline Valid N (listwise) & 173 & & & & \\
\hline
\end{tabular}

\section{Uji Normalitas}

Tabel 3 merupakan uji normalitas sebelum di outlier, data tersebut tidak memenuhi syarat sehingga data tidak berdistribusi dengan normal maka dilakukan outlier data. Tabel 4 uji normalitas setelah outlier dan data berdistribusi dengan normal.

Pengaruh Profitabilitas, Leverage, Ukuran Perusahaan, Sales Growth, dan Kualitas Audit 
Tabel 3 Uji Normalitas Sebelum Eliminasi Outlier

\begin{tabular}{|l|r|r|r|r|r|}
\hline \multirow{2}{*}{} & \multicolumn{1}{|c|}{$\mathrm{N}$} & \multicolumn{2}{|c|}{ Skewness } & \multicolumn{2}{c|}{ Kurtosis } \\
\cline { 2 - 6 } & Statistic & Statistic & Std. Error & Statistic & Std. Error \\
\hline Unstandardized Residual & 213 & 2,738 &, 167 & 14,201 &, 332 \\
\hline Valid N (listwise) & 213 & & & & \\
\hline
\end{tabular}

Tabel 4 Uji Normalitas Sesudah Eliminasi Outlier

\begin{tabular}{|l|r|r|r|r|r|}
\hline \multirow{2}{*}{} & \multicolumn{1}{|c|}{$\mathrm{N}$} & \multicolumn{2}{c|}{ Skewness } & \multicolumn{2}{c|}{ Kurtosis } \\
\cline { 2 - 7 } & Statistic & Statistic & Std. Error & Statistic & \multicolumn{1}{c|}{ Std. Error } \\
\hline Unstandardized Residual & 173 &,- 053 &, 185 &, 161 &, 367 \\
\hline Valid N (listwise) & 173 & & & & \\
\hline
\end{tabular}

\section{Uji Asumsi Klasik}

\section{Uji Multikolinieritas}

Uji multikolinieritas digunakan untuk menguji apakah model regresi ditemukan adanya saling keterkaitan antar variabel independen. Berdasarkan tabel 5 diketahui bahwa nilai tolerance semua variabel independen $>0,10$ dan nilai VIF (Variance Inlfation Factor) nilainya < 10,00. Hal ini menunjukan bahwa model regresi tersebut dinyatakan bebas multikolinieritas dan pengujian dapat dilanjutkan ke tahap berikutnya

Tabel 5 Uji Multikolinieritas

\begin{tabular}{|l|r|r|r|}
\hline \multirow{2}{*}{ Model } & \multicolumn{2}{|c|}{$\begin{array}{c}\text { Collinearity } \\
\text { Statistics }\end{array}$} & \multirow{2}{*}{ Keterangan } \\
\cline { 2 - 3 } & Tolerance & \multicolumn{1}{|c|}{ VIF } & \\
\hline (Constant) & & & \\
\hline ROA &, 847 & 1,180 & Bebas Multikolinieritas \\
\hline DER &, 939 & 1,064 & Bebas Multikolinieritas \\
\hline UKURAN PERUSAHAAN &, 845 & 1,184 & Bebas Multikolinieritas \\
\hline SALES GROWTH &, 958 & 1,044 & Bebas Multikolinieritas \\
\hline UKURAN KAP &, 759 & 1,318 & Bebas Multikolinieritas \\
\hline
\end{tabular}

\section{Uji Heterokedastisitas}

Uji heterokedastisitas bertujuan untuk menguji apakah model regresi linier terjadi ketidaksamaan varian dari residual satu pengamatan ke pengamatan lain. Berdasarkan tabel 6 uji heteroskedastisitas dapat dilihat bahwa nilai signifikasi memiliki nilai lebih besar dari 0,05. Hasil uji heterokedastisitas tersebut memenuhi syarat sehingga data berdistribusi dengan normal.

Tabel 6 Uji Heterokedastisitas

\begin{tabular}{|c|c|c|c|c|c|c|}
\hline \multirow{2}{*}{\multicolumn{2}{|c|}{ Model }} & \multicolumn{2}{|c|}{$\begin{array}{l}\text { Unstandardized } \\
\text { Coefficients }\end{array}$} & \multirow{2}{*}{$\begin{array}{c}\text { Standardized } \\
\text { Coefficients } \\
\text { Beta }\end{array}$} & \multirow[b]{2}{*}{$\mathrm{t}$} & \multirow[b]{2}{*}{ Sig. } \\
\hline & & $\mathrm{B}$ & Std. Error & & & \\
\hline \multirow[t]{6}{*}{1} & (Constant) &,- 012 & ,027 & &,- 446 & ,656 \\
\hline & LAG_ROA &,- 050 & 019 &,- 197 & $-2,611$ &, 070 \\
\hline & DER &,- 003 & 003 &,- 079 & $-1,009$ &, 314 \\
\hline & \begin{tabular}{|l} 
UKURAN PERUSAHAAN \\
\end{tabular} & 001 & 001 &, 120 & 1,467 &, 144 \\
\hline & \begin{tabular}{|l} 
SALES GROWTH \\
\end{tabular} & 017 & ,013 & ,101 & 1,325 &, 187 \\
\hline & \begin{tabular}{|l|} 
UKURAN KAP \\
\end{tabular} &, 000 & 003 &, 004 & 054 & ,957 \\
\hline
\end{tabular}




\section{Uji Autokorelasi}

Tabel 7 Uji Autokorelasi

\begin{tabular}{|c|c|c|c|c|c|}
\hline dl & $\mathbf{d u}$ & $\mathbf{d w}$ & $\mathbf{4 - d u}$ & $\mathbf{4 - d l}$ & Hasil \\
\hline 1,692 & 1,811 & 2,022 & 2,189 & 2,308 & Tidak terjadi gejala autokorelasi \\
\hline
\end{tabular}

Hasil uji autokorelasi diatas menggunakan Durbin-Watson dengan menunjukan nilai yang signifikan 5\% dari jumlah sampel (n) 173 dan jumlah variabel $4(\mathrm{k}=4)$, maka dari tabel DurbinWatson diperoleh nilai dl sebesar 1,692. Nilai du sebesar 1,811, nilai 4-dl sebesar 2,308 dan nilai 4-du sebesar 2,189. Pada tabel diatas DW menunjukan sebesar 2,002 dan jumlah tersebut terletak diantara $\mathrm{du}<\mathrm{dw}<4$-du yaitu $1,692<2,022<2,189$. Maka dapat disimpulkan bahwa tidak ada gejala autokorelasi.

Teknik Analisis

Teknik analisis yang digunakan berupa analisis regresi linier berganda. Hal ini dikarenakan penggunaan variabel independen lebih dari satu dalam penelitian ini.

Tabel 8. Analisis Regresi Linier Berganda

\begin{tabular}{|l|r|r|r|r|r|}
\hline \multirow{2}{*}{ Model } & \multicolumn{2}{|c|}{$\begin{array}{c}\text { Unstandardized } \\
\text { Coefficients }\end{array}$} & $\begin{array}{c}\text { Standardized } \\
\text { Coefficients }\end{array}$ & \multirow{2}{*}{} & \multicolumn{1}{c|}{ t } \\
\cline { 2 - 4 } & \multicolumn{1}{|c|}{ B } & \multicolumn{1}{c|}{ Std. Error } & \multicolumn{1}{c|}{ Beta } & \multicolumn{1}{c|}{ t } \\
\hline (Constant) &, 244 &, 042 & & 8,778 &, 000 \\
\hline LAG_ROA &, 005 &, 030 &, 013 &, 168 &, 007 \\
\hline DER &,- 002 &, 004 &,- 030 &,- 373 &, 010 \\
\hline UKURAN PERUSAHAAN &, 000 &, 002 &, 013 &, 156 &, 877 \\
\hline SALES GROWTH &, 019 &, 020 &, 073 &, 931 &, 353 \\
\hline UKURAN KAP &, 002 &, 005 &, 028 &, 333 &, 740 \\
\hline
\end{tabular}

Berdasarkan tabel 8. dapat diketahui bahwa model persamaan regresi linier berganda adalah sebagai berikut:

ETR $=0,244+0,005$ ROA $-0,002 D E R+0,000$ SIZE+0,019SALES+0,002KA+e

Uji Kelayakan Model (Uji F)

Tabel 9. Uji F ANOVA

\begin{tabular}{|l|l|r|r|r|r|r|}
\hline \multicolumn{2}{|l|}{ Model } & Sum of Squares & \multicolumn{1}{c|}{$\mathrm{df}$} & Mean Square & F & Sig. \\
\hline \multirow{4}{*}{1} & Regression &, 001 & 5 &, 000 & 9,262 &, $003^{\mathrm{b}}$ \\
\cline { 2 - 8 } & Residual &, 175 & 166 &, 001 & & \\
\cline { 2 - 8 } & Total &, 176 & 171 & & & \\
\hline
\end{tabular}

Berdasarkan tabel menunjukan nila $\mathrm{F}$ hitung sebesar 9,262 dengan nilai signifikansi 0,003 . Hal ini menunjukan bahwa model regresi dapat digunakan untuk memprediksi variabel dependen karena nilai signifikasi $<0,05$. Maka disimpulkan bahwa model regresi pada penelitian ini dapat dikatakan layak.

\section{Uji Koefisien Determinasi}

Tabel 10. Uji Koefisien Determinasi $\mathrm{R}^{2}$

\begin{tabular}{|l|r|r|r|r|}
\hline Model & $\mathrm{R}$ & R Square & $\begin{array}{c}\text { Adjusted R } \\
\text { Square }\end{array}$ & $\begin{array}{c}\text { Std. Error of } \\
\text { the Estimate }\end{array}$ \\
\hline 1 &, $088^{\mathrm{a}}$ &, 388 &, 372 &, 032473 \\
\hline
\end{tabular}

Berdasarkan tabel 10 uji koefisien determinasi menunjukan nilai Adjusted R Square sebesar 0,372. Hal ini dapat dikatakan bahwa sebesar 37,2\% variabel tax avoidance dipengaruhi oleh variabel profitabilitas, leverage, ukuran perusahaan, sales growth dan kualitas audit. Sedangkan sisanya sebanyak $62,8 \%$ dipengaruhi oleh variabel lain yang tidak terdapat dalam model penelitian ini. 
Uji Hipotesis (Uji t)

Tabel 11. Uji Hipotesis

\begin{tabular}{|c|c|c|c|c|c|}
\hline \multirow[b]{2}{*}{ Model } & \multicolumn{2}{|c|}{$\begin{array}{c}\text { Unstandardized } \\
\text { Coefficients }\end{array}$} & \multirow{2}{*}{$\begin{array}{c}\begin{array}{c}\text { Standardized } \\
\text { Coefficients }\end{array} \\
\text { Beta }\end{array}$} & \multirow[b]{2}{*}{$\mathrm{t}$} & \multirow[b]{2}{*}{ Sig. } \\
\hline & B & Std. Error & & & \\
\hline (Constant) & 244 & ,042 & & 8,778 &, 000 \\
\hline LAG_ROA &, 005 & 030 & ,013 & , 168 & 007 \\
\hline DER &,- 002 &, 004 &,- 030 &,- 373 &, 010 \\
\hline UKURAN PERUSAHAAN & 000 &, 002 & 013 &, 156 & 877 \\
\hline SALES GROWTH &, 019 &, 020 &, 073 & ,931 &, 353 \\
\hline UKURAN KAP &, 002 &, 005 & ,028 &, 333 &, 740 \\
\hline
\end{tabular}

Pengaruh Profitabilitas terhadap Tax Avoidance

Hipotesis pertama $\left(\mathrm{H}_{1}\right)$ adalah profitabilitas berpengaruh positif terhadap tax avoidance. Berdasarkan hasil dari uji t pada tabel 4.13 menunjukan nilai koefisien $\beta$ untuk profitabilitas diperoleh sebesar 0,005 dengan nilai signifikan 0,007 lebih kecil dari 0,05. Dengan demikian profitabilitas berpengaruh positif terhadap tax avoidance, sehingga $\mathbf{H}_{\mathbf{1}}$ diterima.

Pihak manajerial dituntun oleh para pemegang saham untuk meningkatan laba pada perusahaan agar tercapainya tujuan perusahaan tersebut. Semakin tinggi laba perusahaan maka semakin tinggi nilai ROA. Laba yang meningkat menyebabkan beban pajak yang dibayarkan perusahaan akan semakin meningkat. Hal tersebut menimbulkan keinginan perusahaan untuk melakukan tax avoidance guna meminimalisir beban pajak yang dibayarkan.Hasil penelitian ini sejalan dengan penelitian yang dilakukan oleh (Irianto et al., 2017), (Arinda \& Dwimulyani, 2018) dan (Mahdiana \& Amin, 2020) yang membuktikan bahwa profitabilitas berpengaruh positif terhadap tax avoidance. Namun, penelitian ini tidak sejalan dengan penelitian yang dilakukan oleh (Oktamawati, 2017) dan (Hidayat, 2018) yang membuktikan bahwa profitabilitas berpengaruh negatif terhadap tax avoidance.

\section{Pengaruh Leverage terhadap Tax Avoidance}

Hipotesis kedua $\left(\mathrm{H}_{2}\right)$ adalah leverage berpengaruh negatif terhadap tax avoidance. Berdasarkan hasil dari uji t pada tabel 4.13 menunjukan nilai koefisien $\beta$ untuk leverage diperoleh sebesar - 0,002 dengan nilai signifikan 0,010 lebih kecil dari 0,05. Dengan demikian leverage berpengaruh negatif terhadap tax avoidance, sehingga $\mathbf{H}_{2}$ diterima.

Pengambilan keputusan dengan adanya pendanaan melalui utang akan menimbulkan beban bunga yang timbul dari hutang tersebut. Biaya bunga yang semakin tinggi akan mengurangi beban pajak yang akan dibayarkan, Berkurangnya beban pajak tersebut akan membuat pihak manajerial lebih berhati - hati dalam tax kegiatan tax avoidance. Hasil penelitian ini sejalan dengan (Arinda \& Dwimulyani, 2018) dan (Aprianto \& Dwimulyani, 2019) yang membuktikan bahwa leverage berpengaruh negatif terhadap tax avoidance. Namun, penelitian ini tidak sejalan dengan penelitian yang dilakukan oleh (Oktamawati, 2017) yang membuktikan bahwa leverage berpengaruh positif terhadap tax avoidance.

\section{Pengaruh Ukuran Perusahaan terhadap Tax Avoidance}

Hipotesis ketiga $\left(\mathrm{H}_{3}\right)$ adalah ukuran perusahaan berpengaruh positif terhadap tax avoidance. Berdasarkan hasil dari uji t pada tabel 4.13 menunjukan nilai koefisien $\beta$ untuk ukuran perusahaan diperoleh sebesar 0,000 dengan nilai signifikan 0,877 lebih besar dari 0,05. Dengan demikian ukuran perusahaan tidak berpengaruh terhadap tax avoidance, sehingga $\mathbf{H}_{3}$ ditolak.

Hal ini membuktikan bahwa besar kecilnya ukuran sebuah perusahaan tidak mempengaruhi manajemen dalam melakukan tax avoidance.Pembayaran pajak oleh wajib pajak badan bersifat wajib sehingga ukuran perusahaan tidak dapat dijadikan sebuah beban yang dapat mengurangi beban pajak Apabila perusahaan melakukan tax avoidance akan berisiko tinggi karena dapat merusah citra perusahaan tersebut. Hasil penelitian ini sejalan dengan (Prapitasari \& Safrida, 2019), (Mahdiana \& Amin, 2020) dan (Primasari, 2019) yang membuktikan bahwa ukuran perusahaan tidak berpengaruh terhadap tax avoidance. Namun penelitian ini tidak sejalan JURNAL ILMIAH KOMPUTERISASI AKUNTANSI Vol. 14, No. 2, Desember 2021 : 394 - 403 
dengan penelitian yang dilakukan oleh (Irianto et al., 2017) yang membuktikan bahwa ukuran perusahaan berpengaruh positif terhadap tax avoidance.

Pengaruh Sales Growth terhadap Tax Avoidance

Hipotesis keempat $\left(\mathrm{H}_{4}\right)$ adalah sales growth berpengaruh positif terhadap tax avoidance. Berdasarkan hasil dari uji t pada tabel 4.13 menunjukan nilai koefisien $\beta$ untuk sales growth diperoleh sebesar 0,019 dengan nilai signifikan 0,353 lebih besar dari 0,05. Dengan demikian sales growth tidak berpengaruh terhadap tax avoidance, sehingga $\mathbf{H}_{\mathbf{4}}$ ditolak.

Tingginya sales growth pada sebuah perusahaan akan menghasilkan laba yang tinggi pula. Dengan adanya kenaika sales growth yang sangat signifikan ini akan menimbulkan pengawasan pajak yang dilakukan oleh fiscus. Hal tersebut akan menjadikan manajemen lebih waspada dalam melakukan pengelolaan pajaknya. Hasil penelitian ini sejalan dengan (Aprianto \& Dwimulyani, 2019), (Mahdiana \& Amin, 2020) dan (Primasari, 2019) yang membuktikan bahwa sales growth tidak berpengaruh terhadap tax avoidance. Namun penelitian ini tidak sejalan dengan penelitian yang dilakukan oleh (Wahyuni et al., 2017) yang membuktikan bahwa ukuran perusahaan berpengaruh positif terhadap tax avoidance.

Pengaruh Kualitas Audit terhadap Tax Avoidance

Hipotesis kelima $\left(\mathrm{H}_{5}\right)$ adalah kualitas audit berpengaruh negatif terhadap tax avoidance. Berdasarkan hasil dari uji t pada tabel 4.13 menunjukan nilai koefisien $\beta$ untuk kualitas audit diperoleh sebesar 0,002 dengan nilai signifikan 0,740 lebih besar dari 0,05. Dengan demikian kualitas audit tidak berpengaruh terhadap tax avoidance, sehingga $\mathbf{H}_{5}$ ditolak.

KAP big four maupun KAP non big four sama - sama memiliki tenaga ahli dalam melakukan audit sehingga menghasilkan kualitas audit yang dapat dipercaya dan kompeten. Hal ini menunjukan bahwa KAP melaksanakan tugasnya sesuai standar audit yang telah ditetapkan. Sehingga kualitas audit yang dinilai darii ukuran KAP tidak dapat menentukan tingkat tax avoidance yang dilakukan perusahaan. Hasil penelitian ini sejalan dengan (Arinda \& Dwimulyani, 2018), (Abdillah \& Nurhasanah, 2020) dan (Primasari, 2019) yang menyatakan bahwa kualitas audit tidak berpengaruh terhadap tax avoidance. Namun, penelitian ini tidak sejalan dengan penelitian yang dilakukan oleh (Sulistiono, 2018) yang menyatakan bahwa kualitas audit berpengaruh positif terhadap tax avoidance.

\section{Kesimpulan} bahwa:

Berdasarkan hasil penelitian yang telah diuraikan sebelumnya dapat ditarik kesimpulan

1. Profitabilitas berpengaruh positif terhadap tax avoidance

2. Leverage berpengaruh negatif terhadap tax avoidance

3. Ukuran perusahaan tidak berpengaruh terhadap tax avoidance

4. Sales growth tidak berpengaruh terhadap tax avoidance

5. Kualitas audit tidak berpengaruh terhadap tax avoidance

Berdasarkan hasil pembahasan serta kesimpulan dalam penelitian ini. Saran yang dapat diberikan melalu hasil penelitian ini agar mendapatkan hasil yang baik untuk peneliti selanjutnya agar menambah tahun serta menambah variabel independen agar memberikan sampel yang baik.

\section{Daftar Pustaka}

Abdillah, M. R., \& Nurhasanah. (2020). Pengaruh Risiko Perusahaan, Kualitas Audit Dan Komite Audit Terhadap Tax Avoidance Pada Perusahaan Manufaktur Yang Terdaftar Di Bursa Efek Indonesia Tahun 2015-2018. Ekonomi Dan Bisnis, VOL.13(NO.1), PP.82-98. http://repository.umy.ac.id/handle/123456789/10165

Anggraeni, T., \& Oktaviani, R. M. (2021). Dampak Thin Capitalization, Profitabilitas, Dan Ukuran Perusahaan Terhadap Tindakan Penghindaran Pajak. Jurnal Akuntansi Dan Pajak, 21(02), 390-397. https://doi.org/10.29040/jap.v21i02.1530 
Aprianto, M., \& Dwimulyani, S. (2019). Pengaruh Sales Growth dan Leverage terhadap Tax Avoidance dengan Kepimilikan Institusional Sebagai Variabel Moderasi. Prosiding Seminar Nasional, November, 1-10. https://trijurnal.lemlit.trisakti.ac.id/pakar/article/view/4246

Arinda, H., \& Dwimulyani, S. (2018). ANALISIS PENGARUH KINERJA KEUANGAN DAN KUALITAS AUDIT TERHADAP TAX AVOIDANCE DENGAN GOOD CORPORATE GOVERNANCE SEBAGAI VARIABEL MODERASI. Jurnal Akuntansi Trisakti, 5(1), 123-140.

Diantari, K. W., Mahaputra, I. N. K. A., \& Sudiartana, I. M. (2021). PENGARUH PROFITABILITAS, LIKUIDITAS, KUALITAS AUDIT DAN UKURAN PERUSAHAAN TERHADAP TAX AVOIDANCE PADA PERUSAHAAN MANUFAKTUR YANG TERDAFTAR DI BURSA EFEK INDONESIA TAHUN 2016 - 2018 Kadek. 3(2), 297-307.

Feranika, A., Mukhzarudfa, H., \& Machfuddin, A. (2016). PENGARUH KEPEMILIKAN INSTITUSIONAL, DEWAN KOMISARIS INDEPENDEN, KUALITAS AUDIT, KOMITE AUDIT, KARAKTER EKSEKUTIF, DAN LEVERAGE TERHADAP TAX AVOIDANCE(Studi Empiris Pada Perusahaan Manufaktur di Bursa Efek Indonesia dengan Tahun Pengamatan 2010-2014). 17 (59).

Ghozali. (2016). Aplikasi Analisis Multivariete Dengan Program IBM SPSS. Badan Penerbit Universitas Diponegoro.

Hidayat, W. W. (2018). Pengaruh Profitabilitas, Leverage Dan Pertumbuhan Penjualan Terhadap Penghindaran Pajak. Jurnal Riset Manajemen Dan Bisnis (JRMB) Fakultas Ekonomi UNIAT, 3(1), 19-26. https://doi.org/10.36226/jrmb.v3i1.82

Irianto, B. S., Sudibyo, Y. A., \& Wafirli, A. (2017). The Influence of Profitability, Leverage, Firm Size and Capital Intensity Towards Tax Avoidance. International Journal of Accounting and Taxation, 5(2), 33-41. https://doi.org/10.15640/ijat.v5n2a3

Jensen, M. C., \& Meckling, W. H. (1976). Theory of the Firm: Managerial Behavior, Agency Costs and Ownership Structure. itle.

Jensen, Michael C, \& Meckling, W. H. (1976). Theory of the Firm: Managerial Behavior, Agency Costs and Ownership Structure. 3, 305-360.

Kasmir. (2014). Analisa Laporan Keuangan. PT Raja Grafindo Persada.

Kusufiyah, Y. V., \& Anggraini, D. (2019). Peran Komisaris Independen, Ukuran Perusahaan, Kinerja Keuangan dan Leverage Terhadap Usaha Penghindaran Pajak. E-Jurnal Akuntansi, 26, 1601. https://doi.org/10.24843/eja.2019.v26.i02.p28

Mahdiana, M. Q., \& Amin, M. N. (2020). Pengaruh Profitabilitas, Leverage, Ukuran Perusahaan, Dan Sales Growth Terhadap Tax Avoidance. Jurnal Akuntansi Trisakti, 7(1), 127. https://doi.org/10.25105/jat.v7i1.6289

Mulyadi. (2016). Sistem Akuntansi (4th ed.). Salemba Empat.

Oktamawati, M. (2017). Pengaruh Karakter Eksekutif, Komite Audit, Ukuran Perusahaan, Leverage, Pertumbuhan Penjualan, Dan Profitabilitas Terhadap Tax Avoidance. Jurnal Akuntansi Bisnis, 15(1), 23-40. https://doi.org/10.24167/JAB.V15I1.1349

penghindaran-pajak-membuat-rugi-negara-rp-687-triliun-ini-kata-dirjen-pajak newssetup.kontan.co.id. (n.d.). https://newssetup.kontan.co.id/news/penghindaran-pajakmembuat-rugi-negara-rp-687-triliun-ini-kata-dirjen-pajak

Prapitasari, A., \& Safrida, L. (2019). THE EFFECT OF PROFITABILITY, LEVERAGE, FIRM SIZE, POLITICAL CONNECTION AND FIXED ASSET INTENSITY ON TAX AVOIDANCE (EMPIRICAL STUDY ON MINING COMPANIES LISTED IN INDONESIA STOCK EXCHANGE 2015-2017). Accounting Research Journal of Sutaatmadja (ACCRUALS), 3(2), 247-258. https://doi.org/https://doi.org/10.35310/accruals.v3i2.56

Prima, B. (2019). Tax Justice laporkan Bentoel lakukan penghindaran pajak, Indonesia rugi US\$ 14 juta. Www.Kontan.Co.Id. https://nasional.kontan.co.id/news/tax-justice-laporkanbentoel-lakukan-penghindaran-pajak-indonesia-rugi-rp-14-juta

JURNAL ILMIAH KOMPUTERISASI AKUNTANSI Vol. 14, No. 2, Desember 2021 : 394 - 403 
Primasari, N. H. (2019). Leverage,Ukuran Perusahaan, Profitabilitas,Pertumbuhan Penjualan, Proporsi Komisaris Independen dan Kualitas Audit Terhadap Tax Avoidance. Jurnal Akuntansi Dan Keuangan, 8(2), 1-13.

Sulistiono, E. (2018). PENGARUH PROFITABILITAS, LEVERAGE, DAN KUALITAS AUDIT TERHADAP TAX AVOIDANCE. Jurnal Informasi Perpajakan, Akuntansi Dan Keuangan Publik, 13, 87-110. http://dx.doi.org/10.25105/jipak.v13i1.5009

Wahyuni, L., Fahada, R., \& Atmaja, B. (2017). The Effect of Business Strategy, Leverage, Profitability and Sales Growth on Tax Avoidance. Indonesian Management and Accounting Research, 16(2), 66. https://doi.org/10.25105/imar.v16i2.4686

Zoebar, M. K. Y., \& Miftah, D. (2020). Pengaruh Corporate Social Responsibility, Capital Intensity Dan Kualitas Audit Terhadap Penghindaran Pajak. Jurnal Magister Akuntansi Trisakti, 7(1), 25. https://doi.org/10.25105/jmat.v7i1.6315 